\title{
Emerging Job Opportunities for PharmD Graduates: Looking Outside the Box
}

\author{
Akram Ahmad ${ }^{1 *}$, Muhammad Umair Khan ${ }^{1}$, Anantha Naik Nagappa ${ }^{2}$ and Isha Patel ${ }^{3}$ \\ 1'Department of Clinical Pharmacy, Faculty of Pharmaceutical Sciences, UCSI University, No. 1 Jalan Menara Gading, UCSI Heights, \\ Cheras 56000, Kuala Lumpur, Malaysia \\ 2Department of Pharmacy Management, Manipal College of Pharmaceutical Sciences, Manipal University, Manipal 576104, India \\ 32Department of Biopharmaceutical Sciences, College of Pharmacy Shenandoah University, 1775 N Sector Ct, Winchester, VA 22601, \\ USA
}

In India, PharmD program started in the year 2008 with the aim of increasing the scope of pharmacy to meet the current health care needs. ${ }^{1,2}$ At present, the Pharmacy council of India (PCI) has approved 160 pharmacy schools offering PharmD in India and near about half of them (70) are located in the southern state of Andhra Pradesh. 157 of the 160 PharmD offering schools are private institutions and universities. $^{3}$ A Pharm.D aspirant assumes that after completion of PharmD, he/she can diagnose, treat and provide pharmaceutical care to the patients. In India, pharmacists are still often known as mere compounders/dispensers. The field of pharmacy practice is yet in its initial stages of development and pharmacists with M.Pharm in Pharmacy Practice/Clinical pharmacy are facing difficulties in getting jobs as clinical pharmacists in hospitals or clinical settings since clinical pharmacy is not accepted nation wide., ${ }^{2,4}$ Akram et al 2013, reported poor job satisfaction among pharmacists working in different pharmacy sectors including community pharmacies, hospitals, pharmaceutical industries and academia. ${ }^{5}$

In India, pharmacies often operate without a registered pharmacist. Many a times, pharmacists will rent their certificates to store owners or renters for an annual payment of Rs.5000-10,000/year. ${ }^{4}$ Another issue is that physicians dispense medications without hiring a full time pharmacist. When pharmacists are hired in hospitals, there have no specific job profiles, working conditions are poor, and salaries are too low. In industry, pharmacists work with arts and science graduates instead of fellow pharmacists, get a poor salary (Rs.4000-8000/month) and have to work 12 hours/day. In academia as well, the salary is poor for especially fresher candidates with M. Pharm degree., ${ }^{2,4}$ Their salaries now range from 10-15k/month but previously before 2008 , it was a minimum of $18 \mathrm{k}$. Similarly for PharmD graduates the salaries have dropped from $25-35 \mathrm{k} /$ month to $15-21 \mathrm{k} /$ month.

Many PharmD graduates are unaware about the non-traditional career opportunities available and continue to look for traditional job opportunities in the job market. The aim of the present report is to find the potential employment opportunities for Indian PharmD graduates and scope for development in each specific area.

\section{PHARMACOVIGILANCE}

Major drug companies based in Europe and other developed countries outsource their work to major IT companies in India. There are some advantages to outsourcing such as high manpower costs compared with India and ease of finding trained staff to carry out work effectively. In companies abroad, employers might have to give sick leaves and maternity leaves that can lead to temporary gaps in the workforce and delays in
Submission Date : 20-08-14 Revision Date : 25-08-14 Accepted Date : 03-09-14

DOI: 10.5530/ijper.48.4.2

\section{Address for} correspondence: Dr. Akram Ahmad Department of Clinical Pharmacy Faculty of Pharmaceutical Science UCSI University No.1 Jalan Menara Gading, UCSI Heights, Cheras 56000, Kuala Lumpur, Malaysia Phone: +601112285842 E-Mail: akrampharma67@ gmail.com

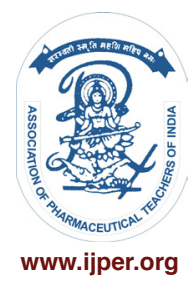


setting up a pharmacovigilance department. At times, a more specialized manpower with special skills might be needed to run the pharmacovigilance department successfully. ${ }^{6}$

Pharmaceutical companies give project work to these IT companies who then finish them as per the company's requirements. Some examples for IT companies where PharmD graduates can seek employment are WIPRO, Accenture, Cognizant, Quintiles, TCS, PPD, I Gate Patni Computers, ICON Solutions and Quantum Solutions, etc. Central drug standards control organizations (CDSCO) has also made it mandatory for all pharma companies those are working in India to establish a pharmacovigilance department and submit pharmacovigilance reports time to time. ${ }^{7}$ As a result, most of these pharmaceutical companies outsource their pharmacovigilance program effectively with the help of these IT companies. These firms work for both clinical trials and post marketing surveillance. Government of India has already launched the National pharmacovigilance program of India (PvPI) which encourages pharmacovigilance reporting from time to time from different health care organizations. ${ }^{8}$ PharmD graduates can be hired for pharmacovigilance reporting because they have good knowledge about pharmacovigilance, clinical and medical terminologies. Also, due to higher salary expectation from medical, dental and nursing graduates, this area provides a good opportunity for PharmD students who would be willing to get paid an average salary Rs.18-26k/month.

\section{ACADEMIA}

PCI has already approved PharmD qualification holders to be eligible for working as lecturers. ${ }^{1}$ Academia is one of the biggest employment sources for PharmD graduates because day by day new pharmacy colleges are initiating PharmD based clinical program. Previously, people working in other areas of pharmacy such as pharmaceutics, medicinal chemistry, pharmacognosy and pharmacology taught PharmD students. ${ }^{2}$ Previously the starting salary in academia for PharmD graduates was Rs.30k/month when there were fewer schools offering PharmD but now it is Rs. $15-20 \mathrm{k}$ only due to increase in the availability of PharmD graduates in the job as well as the availability of more schools offering PharmD program. With a good publication record and work experience of a couple of years in India, PharmD students can find academia jobs abroad in countries such as Malaysia, Ethiopia, Saudi Arabia, and other Middle Eastern and African countries, etc. The salaries in academic institutions abroad are quite high compared to salaries in Indian academic institution.

\section{MEDICAL WRITING/MEDICAL SCIENCE LIAISON / MEDICAL ADVISOR}

Medical writer or medical science liaison or medical advisor is a health care professional who works for pharmaceutical, biotechnology, medical device, and managed care companies. ${ }^{9}$ Currently, it's the largest employer for PharmD graduates. Medical writing or medical liaison involves producing scientific documents by a specialized writer. Medical writer works with physicians, medical scientists and other subject experts. A medical writer produces documents that well and unmistakably describe research results, product usage, and other medical information. Medical writers also work towards preparing documents for regulatory authorities, journals as well as designing guidelines in the form of content, format and structure. ${ }^{9}$ Medical advisors also answer queries asked by physicians providing consulting to pharmaceutical companies. Previously, medical writer positions were primarily filled by medical graduates. However, now, pharmaceutical companies also prefer writers who have sound knowledge of English language and as well as writers who are well acquainted with scientific and medical technical words. ${ }^{9}$ The starting salary for medical writers ranges from Rs. 15 to $20 \mathrm{k} /$ month.

Medical advisors or scientific advisors can work in clinical research and sales or marketing department within the pharmaceutical companies. ${ }^{10}$ They are responsible for providing solutions for medical and scientifically related queries. Their main job is to provide publications related to their company brands besides developing scientific tools to perform successfully their jobs, participating in discussions with other stake holders, participating in cross functional interactions, attending scientific congresses etc. ${ }^{10}$ Medical advisors are also responsible for duties such as maintaining up to date clinical knowledge about their therapeutic are as, performing review from time to time, changing promotional resources, checking regulatory documents compliance with concerned guidelines and regulations, and providing therapeutic area training as needed. ${ }^{10}$ Most of the company hires medical graduates for this job but now pharmacy and other allied health care graduates are also hired. PharmD students can be potential candidates that can be hired as substitutes for medical graduates who are hired to perform the same role with a 3-4 times higher salary. Salary as such in this area for PharmD graduates is very high compared with other 
job roles. Medical science liaison also has similar job role in the industry.

\section{IT SECTOR- MEDICAL BILLING, MEDICAL CODING AND INSURANCE CLAIM}

There is a availability of high number of jobs in medical billing, medical coding and in insurance claim. Medical coding experts play a key role in the medical billing process. Every visit of the patient receives health care from doctor office, outpatient clinic or in hospital facility, the provider must document the services provided. The medical coder abstracts the information from the documentation, assigns the appropriate codes, and creates a claim to be paid, whether by a commercial payer or the patient. ${ }^{11}$ Most of the people working are undergraduates or post graduates in science, nursing, pharmacy and allied health sciences; specially those with an extensive knowledge about physiology, anatomy and medical terminology. For this job role, it is also necessary to become well-known with diverse types of insurance schemes, regulations, compliance, the coding community's three critical resource books and ICD-9-CM along with their corresponding codes and guidelines. ${ }^{11}$ Hence for this job,the pharmacists are the most qualified candidates. Starting salary for this job ranges from Rs.12-18k/month.

Health insurance industry is another unpredicted area that is booming for Pharm. D graduates. It involves evaluating the claimed prescriptions and establishing their actuality for patient bill compensation in a competent, and professional manner. The demand for health insurance is increasing in India and the Indian governmentis also trying to provide mandatory insurance to its citizens so in the future, the demand for working in the health insurance industry will be very high.

\section{CONTRACT RESEARCH ORGANIZATIONS (CRO)/ INDUSTRY}

Contract research organizations work for pharmaceutical, biotechnology, medical device industry to perform research and developmental work on a contractual basis. For pharmaceutical companies, CROs provide consultation for services such as development of medications, biologic assay development, commercialization, preclinical research, clinical research, clinical trials, and pharmacovigilance. ${ }^{12}$ In pharmaceutical industry as well, newly hire PharmD graduates mostly work as clinical research coordinators (CRC) and after 1-2 years of experience, are promoted to clinical research associates (CRA). The starting salary in pharmaceutical industry is Rs.12-22k/ month based on the company and work location. In future, PharmD graduates might be appointed as prin- cipal investigators and co-investigators in clinical trials along with medical graduates with a master's degree in pharmacology or AYUSH physicians with a Masters in clinical pharmacology and therapeutics. Starting salary in CRC is Rs.10-15k/month.

However, the future scope of CRO is doubtful as Supreme Court has banned new clinical trials in the country since many clinical trials companies suspected for illegal and unethical activities. ${ }^{13}$ But still India is the big market for generics so research officers will always be required for bio-equivalence and bio-waiver studies.

\section{CORPORATE HOSPITALS}

Many PharmD graduates work in corporate hospitals as clinical pharmacists and prescription analysts. Some of the important work in corporate hospitals for clinical pharmacists is checking medication errors in prescriptions as well in the indent given to patients during their hospital stay and during discharge, entering medication in a prescribed format, updating the drug formulary in the hospitals, preparing chemo admixtures whenever required especially for the oncology or other departments, going for ward rounds with health care team and discharging summary checks for medications, monitoring, documenting and reporting adverse drug reactions, answering drug related queries of all health care professionals as well as the patients, preparing and submitting monthly reports to the clinical pharmacologist. ${ }^{14}$ For getting international hospital accreditation in India, it is necessary to maintain or establish clinical pharmacy services. Employing PharmD graduates therefore, has become very important for Indian hospitals seeking such accreditation. ${ }^{15}$ Many corporate hospitals in India such as Apollo Hospitals, Wockhrdt, Rock land, and Asia Columbia are hiring M.Pharm graduates with a specialization in pharmacy practice or pharmacology or PharmD graduates. The starting salary in hospitals is low and can range from Rs.10-15k/month. It is a good option for those who want to work as clinical pharmacists or hospital pharmacists abroad because most of the hospitals want job candidates with a 2-3 year work experience in accredited hospitals. Some of the countries that PharmD graduates can work in after giving accreditation exams are USA, Qatar, Saudi Arabia, United Arab Emirates, etc.

\section{COMMUNITY PRACTITIONER}

Pharmacists can work as emergency medicine and therapeutics specialists independently without the presence of a physician. ${ }^{16}$ They can prescribe medicines for small, epidemic, endemic, pandemic and chronic diseases such as hypertension, diabetes, cardiovascular 
disorders, antibiotic therapies, etc. They can also work as drug experts, drug interaction specialists, drug food interaction specialists and nutritionists for patients and the health care industry. However, there could be variation in these functions of pharmacy among different states of India. Pharmacists can open their own community pharmacy and provide pharmaceutical care like blood glucose checkup for diabetes patients, blood pressure check for hypertension patients and dietary counseling to patients for their diet and recommend life style modifications. Currently, many pharmacies run without qualified pharmacists and the presence of services provided by PharmD graduates will create a great deal of difference in enhancing patient care. ${ }^{5}$ PharmD graduates, on the other hand, charge for the services they provide. Recently, a faculty member from a private pharmacy institution in India has started one such organization known as ANN Pharma Care and Wellness LLP. This organization is managed by PharmD in terms and it provides patient education and chronic disease care (pharmaceutical care (FIP-WHO model), diabetes pharmaceutical care, hypertension pharmaceutical care), home medication review, patient counseling and reconciliation of prescription, information services, drug information, generic drug price information, drug-drug and drug-food interaction information pharmacovigilance consulting to the hospitals, private practitioners and patients on the matters of drug, disease and lifestyle. ${ }^{17}$

\section{OTHER}

Product Management Team (PMT) is a core team of marketing development in a pharmaceutical organization, which oversees the overall marketing plan for a specific product and is responsible for profit or loss generated by that particular brand. ${ }^{18}$ PMT also trains the marketing executives that are newly hired by the company or for any new product launch. Previously, those having a degree in pharmacy combined with a management degree were preferred for PMT jobs because the job profile needed knowledge about medical, management and good communications. ${ }^{18}$ Some companies preferred candidates with a pharmacy degree and an experience of $2-3$ years in marketing. PharmD is a sufficient qualification for this job because PharmD graduates have a good knowledge base about clinical research, management and communication skills. The salary is also very high compared to any of the other jobs.

Now-a-days, many retail chain pharmacies are operating in the country. These companies mostly hire pharmacists with a 2 year diploma to work in the pharmacy. These diploma holders don't have sufficient knowl- edge compared to pharmacists with a 4 year degree or PharmD enrolled in a 6 year program. For instance, Apollo Pharmacy, Med plus and Guardian pharmacy are such retail chain pharmacies that employ B.Pharm or M. Pharm graduates under the job title of an "Executive in training and development" (Technical/Soft Skills Trainer). The job description mainly comprises of traveling and delivering training programs to newly hired and existing employees about plan and induction. ${ }^{14}$ Now, even Pharm. D graduates can procure jobs in this sector. Some other job roles for pharmacists are medical reviewing, sales, marketing, medical tourism, Business Process Outsourcing (BPO), Knowledge Process Outsourcing (KPO) and working as a procurement officer in state level government medical companies like Tamil $\mathrm{Nadu}$ medical service corporation (TNMSC), Kerala Medical Services Corporation (KMSCL), West Bengal Medical Services Corporation (WBMSC) etc.

\section{CONCLUSION}

Pharmacies in India are facing many issues. For small scale organizations, a medical graduate might be too expensive and Pharm.D graduates can be a reasonable alternative. Pharm.D graduates have various job avenues besides the traditional ones. The pharmacist should be cognizant of these opportunities and should be able to advance their talents in these non-conventional areas.

\section{REFERENCES}

1. Pharmacy Council of India. available from, http://www.pci.nic.in/ [Last cited on 2014 July 28].

2. Ahmad A, Srikanth BA, Patel I. Indian Pharm.D: Should it be pursued? Arch Pharm Pract. 2014; 5(2): 97-8.

3. Centre's efforts to launch Pharm D course in govt colleges fails to take off, allocation of Rs.824 cr may lapse. available from: http://www.pharmabiz.com/ NewsDetails.aspx?aid=83413\&sid=1 [Last cited on 2014 July 28].

4. Ahmad A, Atique S, Balkrishnan R, Patel I, Pharmacy profession in India: Current scenario and Recommendations. Ind J Pharm Edu Res. 2014; 48(3):12-5.

5. Ahmad A, Isha Patel. Job satisfaction among Indian pharmacists. J Pharm Bioallied Sci. 2013; 5(4): 326.

6. Pharmacovigilance Outsourcing. Available from: http://www. europeanpharmacovigilance.com/ [Last cited on 2014 July 28].

7. Brian Edwards. How should you safely outsource pharmacovigilance to an Indian contract research organization? Indian J Pharmacol. 2008; 40(I1): S24-7.

8. Akram Ahmad, Isha Patel, Rajesh Balkrishnan GP, Mohanta Manna PK. An evaluation of knowledge, attitude and practice of Indian pharmacists towards adverse drug reaction reporting:A pilot study. Perspect Clin Res. 2013; 4(4): 204-10.

9. Suhasini Sharma. How to Become a Competent Medical Writer? Perspect Clin Res. 2010; 1(1): 33-7.

10. Gupta SK, Nayak RP. An insight into the emerging role of regional medical advisor in the pharmaceutical industry. Perspect Clin Res. 2013; 4(3):186-90.

11. Medical Coding. available from: https://www.aapc.com/medical-coding/ medical-coding.aspx [Last cited on 2014 July 28].

12. Imran M, NajmiAK, Rashid MF, Tabrez S, Shah MA. Clinical research regulation in India-history, development, initiatives, challenges and controversies: Still long way to go. J Pharm Bioallied Sci. 2013; 5(1): 2-9. 
13. Supreme Court stands firm on clinical trial ban. available from: http://www. thehealthsite.com/news/supreme-court-stands-firm-on-clinical-trial-ban/ [Last cited on 2014 July 28].

14. Current openings, Apollopharmacy. Available from: http://www. apollopharmacy.in/careers [Last cited on 2014 July 28]

15. Hariharan S, Sankar V, Ramanathan M. The Road ahead for the PharmD Program in India. Pharma Times. 2012; 44(9):17-9.
16. Non Physician Practitners in Indian health care Services. available from: http://www.ncaiprc.org/files/NCAI\%20paper\%20non\%20physician $\% 20$ providers\%20082709_0.pdf [Last cited on 2014 July 28].

17. ANN Pharma Care and Wellness LLP, Services offered, available from: http:// www.annpharmacare.com/ [Last cited on 2014 July 28].

18. Career in pharma product management, Available from: http://pharma. financialexpress.com/20090531/pharmalife01.shtml [Last cited on 2014 July 28]. 